\title{
Electrophoretic study of the physico-chemical characteristics of Bence-Jones proteinuria and its association with kidney damage
}

\author{
M C Diemert, L Musset, O Gaillard, S Escolano, A Baumelou, F Rousselet, J Galli
}

\begin{abstract}
Aim-To identify a physico-chemical criterion, or set of criteria, explaining and possibly predicting the nephrotoxic behaviour of Bence-Jones proteins (BJP). Methods-The electrophoretic mobility and isoelectric point (pI) of $92 \mathrm{BJP}$ isolates were determined using various electrophoresis procedures on polyacrylamide gel. The proportions of monomers and dimers were determined using sodium dodecyl sulphate-polyacrylamide gel electrophoresis (SDS PAGE) in 58 cases. PAGE data for $10 \mathrm{BJP}$ isolates were used to construct Ferguson plots and titration curves.
\end{abstract}

Results-The distribution of electrophoretic mobility and $p I$ values was bimodal and showed a positive correlation when the pI was above 6. The values of these two parameters in 22 patients with renal impairment were not significantly different from those in the patients without renal impairment, and the statistical analysis showed no predictive value for the onset of renal impairment. However, patients excreting the $\lambda$ light chain isotype had a $2 \cdot 8$-fold higher risk of developing renal impairment compared with the other patients. Studies of the charge variation of the protein with $\mathrm{pH}$ indicated three types of behaviour, suggesting that the charge of BJP is highly variable at physiological pH.

Conclusion-It is important to study not only the positivity or negativity of the BJP charge at a given $\mathrm{pH}$, but also its intensity. The study of the BJP titration curves in patients with renal impairment suggests that a low charge at physiological urinary pH could predict renal impairment.

(F Clin Pathol 1994;47:1090-1097)

The presence of free monoclonal light chains-Bence-Jones protein (BJP) -in the urine of patients with myeloma is associated with the onset of kidney damage, a characteristic complication of this disease..$^{1-4}$

For reasons as yet undetermined, the severity of renal disease varies among patients. ${ }^{5-9}$ This depends both on the intrinsic properties of the protein (degree of polymerisation, isoelectric point ( $\mathrm{pI}$ ), and charge) and on the composition of serum and urine. ${ }^{10}$ Studies undertaken in recent years both in animals ${ }^{11-17}$ and in humans ${ }^{18-22}$ support this association. Indeed, light chain polymerisation seems to have a role in the development of renal lesions, ${ }^{1823}$ giving an importance to $\mathrm{pI}, 1119$ which has been contested. ${ }^{24}{ }^{25}$ The degree of polymerisation is generally determined by denaturing electrophoresis which may affect the behaviour of BJP.

In patients with BJP and renal impairment we have noticed a peculiar migration of urinary BJP in polyacrylamide gel in native conditions, suggesting an unusual degree of polymerisation. This led us to study the degree of polymerisation in native conditions, in patients with Bence-Jones proteinuria, with and without renal impairment, and to compare the results with those obtained by methods involving denaturing media. Isoelectrofocusing was combined with these electrophoretic techniques, which were carried out in highly standardised conditions. The aim was to identify a physico-chemical criterion or set of criteria that could explain and possibly predict the nephrotoxicity of BJP.

\section{Methods}

We studied the urine samples of 92 patients (54 men and 38 women; mean age 64.9 and 63.8 years, respectively) with a monoclonal gammapathy detected and typed using electrophoresis and immunoelectrophoresis. The patients were recruited in comparable numbers by the Haematology, Internal Medicine, and Nephrology units of our institution (30, 22 , and $21 \%$, respectively). A smaller proportion of patients were recruited by the Rheumatology (10\%) and other units (17\%).

The underlying illnesses included lymphoproliferative syndromes with monoclonal IgG in $34 \%$ of cases (31/92), IgA in $24 \%$ (22/92), $\operatorname{IgM}$ in $9 \%(8 / 92)$, and IgD in $4 \%(4 / 92)$. Light chain abnormalities represented only $28 \%(25 / 92)$ of the cases. In this latter group the $\kappa$ and $\lambda$ isotype distribution was, respectively, $44 \%(11 / 25)$ and $56 \%(14 / 25)$, proportions equivalent to those in the overall population: $46 \%(42 / 92)$ and $54 \%(50 / 92)$.

At the time of the study 22 of the 92 patients had renal impairment, with creatinemia above $150 \mu \mathrm{mol} / 1$. Clinical and laboratory findings in these patients at diagnosis are shown in table 1 . The serum monoclonal constituents were distributed as follows: $55 \%$ $(12 / 22)$ were free light chains (eight $\lambda$ and four $\kappa$ isotypes); $45 \%(10 / 22)$ were mono- 
Table 1 Laboratory findings at diagnosis of renal failure

\begin{tabular}{|c|c|c|c|c|c|c|c|c|c|}
\hline \multirow{2}{*}{$\begin{array}{l}\text { Case } \\
\text { No }\end{array}$} & \multirow[b]{2}{*}{ Sex/Age } & \multirow{2}{*}{$\begin{array}{l}\text { Serum } \\
\text { monoclonal } \\
\text { components }\end{array}$} & \multirow{2}{*}{$\begin{array}{l}\text { Creatine } \\
(\mu \mathrm{mol} / \mathrm{l})\end{array}$} & \multirow{2}{*}{$\begin{array}{l}\text { Calcium } \\
(\text { mmolll) }\end{array}$} & \multirow{2}{*}{$\begin{array}{l}\text { Phosphorus } \\
\text { (mmolll) }\end{array}$} & \multirow{2}{*}{$\begin{array}{l}\text { Uric } \\
\text { acid } \\
(\mu \mathrm{mol} / \mathrm{l})\end{array}$} & \multicolumn{3}{|c|}{ Precipitating events } \\
\hline & & & & & & & Drugs & $E C D H$ & $I V P$ \\
\hline 1 & M/75 & $\operatorname{Ig} A \lambda$ & 800 & $2 \cdot 27$ & $1 \cdot 8$ & 336 & - & - & - \\
\hline 2 & $F / 46$ & $\lambda$ & 800 & $2 \cdot 5$ & $2 \cdot 3$ & 600 & - & - & - \\
\hline 3 & M/68 & $\begin{array}{l}\operatorname{IgA} \lambda+ \\
\operatorname{IgG} \lambda+\lambda\end{array}$ & 648 & $2 \cdot 01$ & $1 \cdot 44$ & 569 & Chemotherapy & - & - \\
\hline 4 & $\mathrm{~F} / 67$ & $\lambda$ & 156 & $2 \cdot 88$ & $1 \cdot 20$ & 524 & Chemotherapy & - & - \\
\hline 5 & M/61 & $\operatorname{IgD} \lambda$ & 286 & $2 \cdot 35$ & 1.5 & 510 & NSAIDs & - & - \\
\hline 6 & $\mathrm{~F} / 66$ & $\kappa$ & 280 & $2 \cdot 41$ & $1 \cdot 3$ & 435 & - & - & ++ \\
\hline 7 & $F / 71$ & $\operatorname{IgG} \kappa$ & 210 & 2.51 & $1 \cdot 37$ & 434 & - & - & - \\
\hline 8 & $\mathrm{~F} / 58$ & $\operatorname{IgA} \lambda+\lambda$ & 457 & $3 \cdot 24$ & $2 \cdot 6$ & 511 & - & - & - \\
\hline 9 & M/49 & $\kappa$ & 674 & 3.45 & $2 \cdot 2$ & 172 & - & - & - \\
\hline 10 & $F / 69$ & $\kappa$ & 720 & 3.0 & $2 \cdot 3$ & 528 & NSAIDs & - & - \\
\hline 11 & $\mathbf{M} / 70$ & $\mathrm{IgG} \kappa$ & 686 & $2 \cdot 38$ & $1 \cdot 17$ & 360 & - & - & ++ \\
\hline 12 & $\mathrm{~F} / 62$ & $\operatorname{IgG} \lambda+\lambda$ & 600 & $2 \cdot 25$ & 0.88 & 218 & - & - & - \\
\hline 13 & $\mathrm{M} / 70$ & IgA. & 300 & $2 \cdot 3$ & $1 \cdot 16$ & 333 & - & - & - \\
\hline 14 & $\mathrm{M} / 72$ & $\operatorname{IgD} \lambda+\lambda$ & 890 & $2 \cdot 83$ & $2 \cdot 38$ & 610 & - & - & - \\
\hline 15 & $M / 75$ & $\operatorname{IgG} \lambda+\lambda$ & 517 & NA & NA & NA & NA & NA & NA \\
\hline 16 & F/58 & $\lambda$ & 197 & $2 \cdot 37$ & $1 \cdot 16$ & 298 & - & - & - \\
\hline 17 & $F / 60$ & $\lambda$ & 870 & $2 \cdot 17$ & $2 \cdot 43$ & 330 & - & ++ & - \\
\hline 18 & $F / 63$ & $\lambda$ & 960 & $2 \cdot 11$ & $2 \cdot 72$ & 528 & - & - & ++ \\
\hline 19 & M/70 & $\kappa$ & 251 & $2 \cdot 3$ & 1.04 & 441 & NSAIDs & - & - \\
\hline 20 & M/85 & $\lambda$ & 258 & NA & NA & NA & NA & NA & NA \\
\hline 21 & $\mathrm{M} / 70$ & $\lambda$ & 357 & NA & NA & NA & NA & NA & NA \\
\hline 22 & M/44 & $\lambda$ & 600 & $2 \cdot 19$ & $1 \cdot 6$ & 490 & - & - & - \\
\hline
\end{tabular}
available.

clonal immunoglobulins, of which $18 \%(4 / 22)$ were IgA with $\lambda$ light chains, $18 \%(4 / 22)$ were IgG with $\kappa$ or $\lambda$ light chains, and $9 \%(2 / 22)$ were $\operatorname{IgD}$ with $\lambda$ light chains. None of the patients had detectable circulating monoclonal IgM. Seventy three per cent $(16 / 22)$ of the urinary light chains were of the $\lambda$ isotype in the patients with renal impairment, compared with $49 \%(34 / 70)$ in those with normal renal function.

In the group of patients with renal impairment for whom clinical and biological data were available (main data were not available for three patients), nine of 19 (47\%) presented with acute renal failure as the initial manifestation of dysglobulinaemia. Eight of $19(42 \%)$ whose presenting symptoms were more typical of multiple myeloma had had renal impairment before. Hypercalcaemia was found in five of $19(26 \%)$ patients. Hyperuricaemia was seen in eight of $19(42 \%)$ patients, exceeding $600 \mu \mathrm{mol} / 1$ in one, while another was dehydrated. Radiocontrast studies were implicated in three patients and nephrotoxic drugs in five (three with nonsteroidal anti-inflammatory agents and two with chemotherapy). Five (26\%) patients were free of these factors.

Urinary BJP, measured by electrophoresis, represented at least $30 \%$ of total proteinuria in the 92 patients (total mean proteinuria = $1 \cdot 3 \mathrm{~g} / \mathrm{l})$

Twenty four hour urine specimens were collected at the bedside and stored in the laboratory for 72 hours at $4^{\circ} \mathrm{C}$, without preservatives.

Samples containing more than $3 \mathrm{~g} / \mathrm{l}$ of protein were diluted in appropriate buffer (depending on the electrophoresis method), or in distilled water (for isoelectric focusing). All electrophoretic migrations were carried out with the Phast-System (Pharmacia, Uppsala, Sweden).
Native polyacrylamide gel electrophoresis (PAGE) separates components on the basis of their size, net charge, and conformation. It is one of the methods used for studying the composition and structure of native proteins, without denaturing agents or detergents, such as sodium dodecyl sulphate (SDS).

One microlitre of urine from each patient was deposited on 8-25 Phastgel gradient (8\% and $25 \%$ acrylamide gel gradient). Migration was run at a $\mathrm{pH}$ close to 8 , according to the manufacturer's instructions, with a slight modification in the migration time (the end of migration was programmed at $350 \mathrm{Vh}$ ). Molecular mass calibration was carried out using the Pharmacia high molecular weight kit. When the BJP separated into several bands, only the main species was taken into account.

For denaturing, 58 of the 92 urine specimens were treated with $2.5 \%$ SDS, without mercaptoethanol, and heated for five minutes at $100^{\circ} \mathrm{C}$. One microlitre of sample was deposited on an 8-25 Phastgel gradient. Electrophoresis was carried out according to the manufacturer's instructions, with slight modifications according to the method of Jackson et $a^{26}$ involving the migration time (end programmed at $90 \mathrm{Vh}$ ). The gel was calibrated with the Pharmacia low molecular weight kit.

Ferguson plots were constructed for $10 \mathrm{BJP}$ isolates, to study their charge and size. Relative mobility was determined using PAGE, with three known concentrations of acrylamide $(T=7.5,12$, and $20 \%)$ in native conditions. ${ }^{27}$

For isoelectric focusing, $1 \mu \mathrm{l}$ of untreated urine sample was deposited on the midline of Phastgel IEF 3-9 plates. Migration was run according to the manufacturer's instructions. The gel was calibrated using the Pharmacia isoelectric focusing protein calibration kit. 
Figure 1 (a) Native polyacrylamide gradient gel electrophoresis pattern and (b) isoelectric focusing of a urinary BfP isolate (case 6). Lane 1, 24 hour urine; lane 2, fresh urine; lane 3, fresh urine collected on butanol; lane 4, fresh urine collected on a mixture of bovine serum albumin (not pure) and butanol; lane 5, fresh urine collected on 2-mercaptoethanol. The far right lane is the standard: (a) molecular masses in kilodaltons and (b) isoelectric point in $\mathrm{pH}$ units indicated on left.

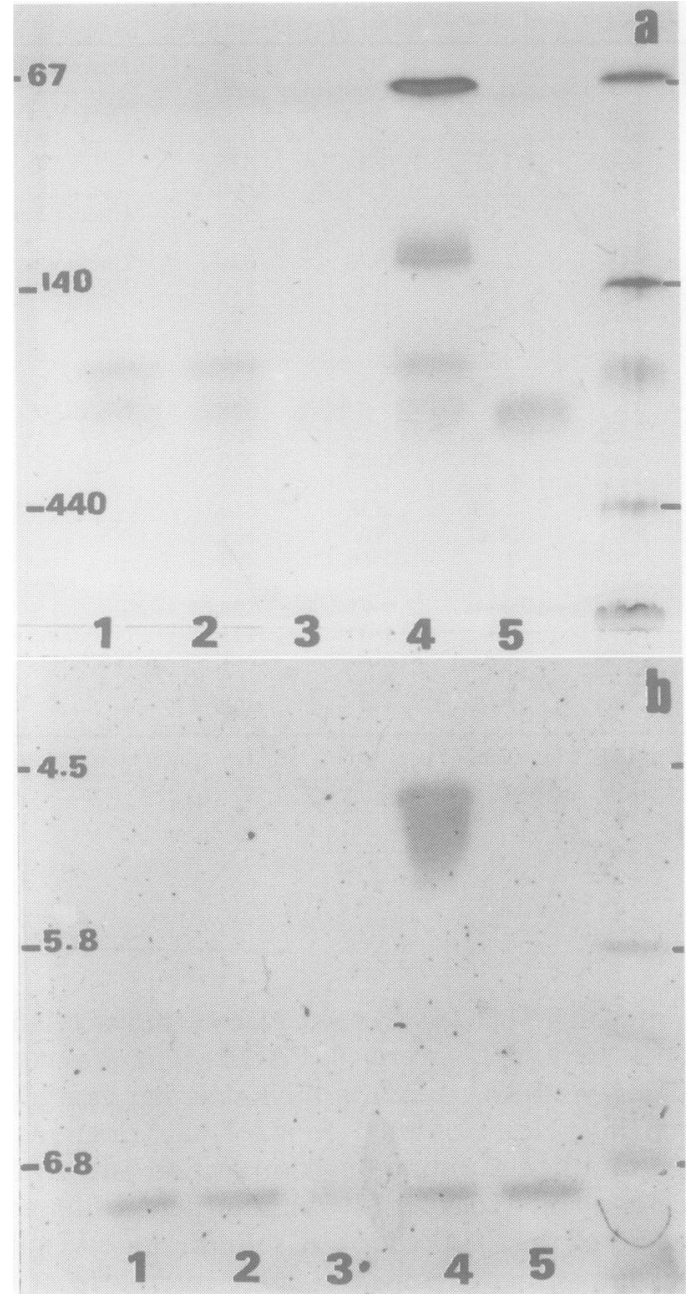

For two-dimensional focusing, Phastgel IEF 3-9 was used, according to the manufacturer's instructions, by depositing $3 \mu \mathrm{l}$ of urine on the midline. The titration curves were established with $10 \mathrm{BJP}$ isolates, six of which were from patients with renal impairment. Human albumin (Sigma, St Louis Missouri, USA) was used as a control ( $\mathrm{pI}=$ $4 \cdot 8)$.

With the aim of detecting BJP specifically, we applied a semi-dry electroblotting method (an extension of the Phast-System to PhastTransfer) to the different types of gel cited above. Protein was transferred to nitrocellulose membranes (BA 85, 0.45 $\mu \mathrm{m}$ Schleicher \& Schull) over 10 to 15 minutes with a potential difference of $20 \mathrm{~V}$ to $25 \mathrm{~mA}$, at $15^{\circ} \mathrm{C}$, using a TRIS-glycine transfer buffer (TRIS $25 \mathrm{mM}$, glycine $192 \mathrm{mM}$, methanol $20 \% \mathrm{v} / \mathrm{v}$ ), impregnating three sheets of filter paper (Phast Transfer filter paper, $50 \times 50 \mathrm{~mm}$ ) placed on each side of the nitrocellulose gel assembly. After transfer, the membrane was immersed in a saturating solution of skimmed powdered milk (Regilait, Lyon, France) at $50 \mathrm{~g} / 1$ in $0.15 \mathrm{M} \mathrm{NaCl}$ for one hour at $45^{\circ} \mathrm{C}$. After drying, the membrane was incubated for 40 minutes in goat monospecific antibodies for human free $\kappa$ or $\lambda$ light chains (Atlantic Antibodies, Stillwater, Minnesota, USA) and diluted 1 in 200 in the saturating solution containing Tween $20(0.20 \mathrm{ml} / \mathrm{l})$. After four five minute washes in $0.15 \mathrm{M} \mathrm{NaCl}$-Tween

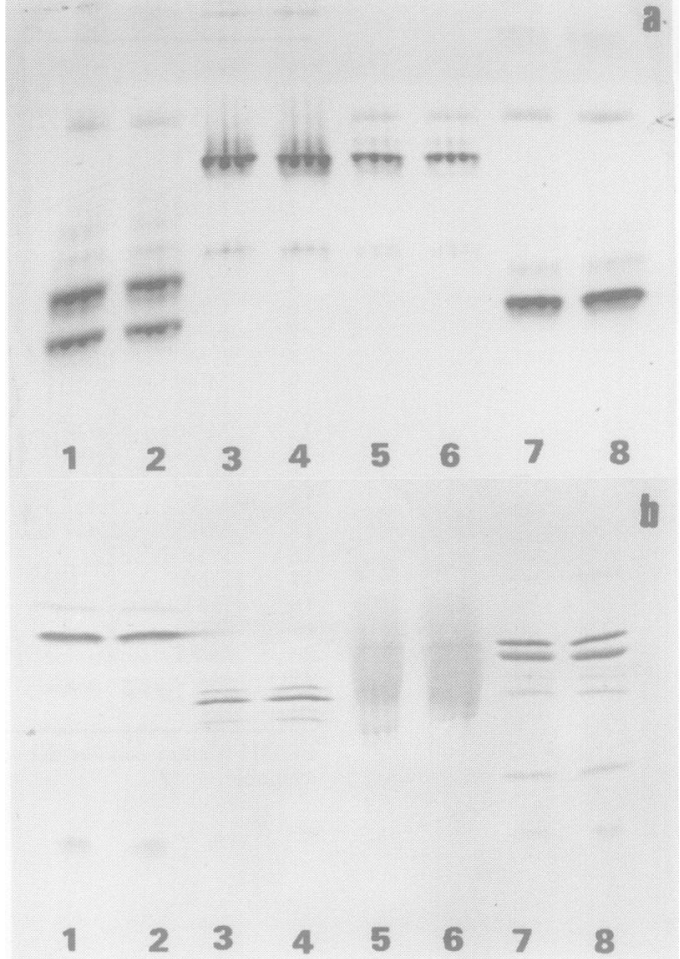

Figure 2 (a) Native polyacrylamide gradient gel electrophoresis pattern and (b) isoelectric focusing of four urinary BfP isolates, before and after storage for 72 hours at $4^{\circ} \mathrm{C}$. Lanes $1-3-5-7$, before storage; lanes 2-4-6-8, after storage.

$20(0.20 \mathrm{ml} / \mathrm{l})$, the membrane was incubated with alkaline phosphatase labelled antigoat IgG antibodies (EC 3.1.3.1; Jackson Immuno Research Labs. Inc., West Grove, Philadelphia, USA) and diluted 1 in 2000 in $0 \cdot 15 \mathrm{M} \mathrm{NaCl}$. After four further washes ( NaCl-Tween 20), enzyme activity was revealed with, as substrate, equal parts of naphthol-As-Mx (Sigma; 0.4 g/l) in TRISHC1 $0.2 \mathrm{M}$ buffer and an aqueous solution of Fast Red (Sigma) at $6 \mathrm{~g} / \mathrm{l}$. Revelation was stopped after 10 minutes by rinsing with distilled water.

Mean values were compared by using Student's $t$ test. The predictive value of the various factors (isotype of the light chain, "migrational" molecular mass, and pI) for the onset of renal impairment was assessed using unifactorial and then multifactorial logistic regression models. All calculations were performed on SAS software (SAS Institute Inc., Cary, North Carolina, USA).

\section{Results}

EFFECT OF URINE COLLECTION AND STORAGE CONDITIONS ON ELECTROPHORETIC PROFILE The effects of urine collection and storage conditions on the electrophoretic profile are shown in figs 1 and 2 . The results showed that relative to fresh urine, there was no change in native PAGE gradient electrophoresis and isoelectric focusing pattern after 24 hours of storage, with or without stabilisers (fig 1). After 72 hours of storage at $4^{\circ} \mathrm{C}$, four different BJP isolates showed no change in the same electrophoretic profiles (fig 2). 
Figure 3 Frequency distribution of the migrational molecular masses of 92 BfP isolates measured using $8-25 \%$ $P A G E$ in native conditions.
Figure 4 Percentage distribution of the patients with renal impairment

(घ) and those with normal renal function ( $\square)$, according to the mobility of the BfP isolate, expressed as "migrational" molecular mass by means of gradient PAGE, in native conditions. The most frequent molecular masses are divided into four classes from 0 to 400 kilodaltons.

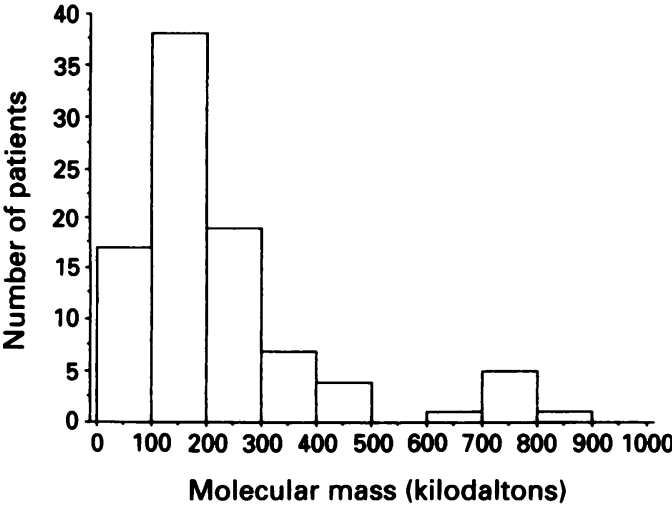

MOLECULAR MASSES IN NATIVE CONDITIONS The frequency distribution of the molecular masses of BJP, measured in native conditions and identified by immunoblotting, is shown in fig 3. The latter shows a bimodal distribution, $93 \%$ of BJP having a "migrational" molecular mass of 50 to 450 kilodaltons, and $7 \%$ with values between 600 and 900 kilodaltons. This distribution was identical for $\kappa$ and $\lambda$ type $\mathrm{BJP}$, and the "migrational" molecular masses were most often between 100 and 200 kilodaltons.

In the group of patients with renal impairment the mean "migrational" molecular mass was 206 kilodaltons, and was not significantly different from that in the group of patients with normal renal function $(\bar{x}=215$ kilodaltons). The distribution of the patients with renal impairment according to the "migrational" molecular mass, classified in increasing class values, showed that the proportion of patients with renal impairment increased from one class to another, although the difference between each class was not significant (fig 4).

\section{MOLECULAR MASS IN DENATURING} CONDITIONS

The study of the electrophoretic pattern obtained in a given gel in the presence of SDS showed the simultaneous presence of monomers (M) and dimers (D) in variable proportions in the $58 \mathrm{BJP}$ isolates analysed. Sixty two per cent $(36 / 58)$ of the BJP isolates were richer in dimers $(M: D$ of $<1)$ and showed a predominance of the $\lambda$ isotype ( $\kappa: \lambda$

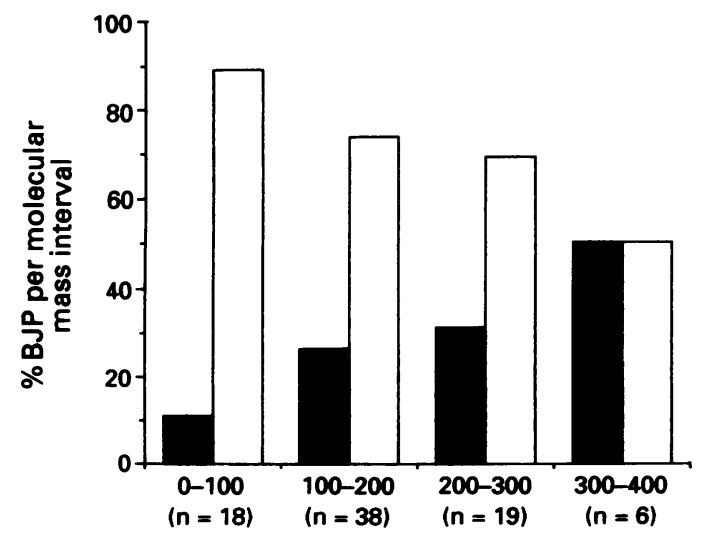

Molecular mass intervals (kilodaltons)

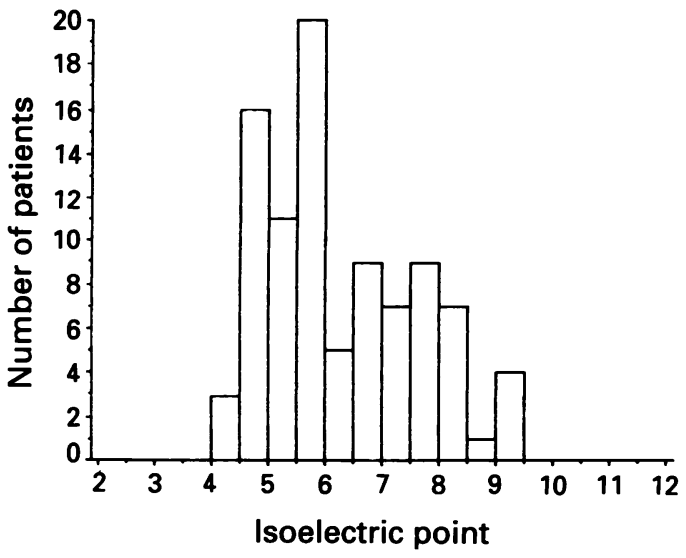

Figure 5 Frequency distribution of the isoelectric points (pI) of 92 BFP isolates measured by isoelectric focusing on polyacrylamide gel. The pH gradient was from 3 to 9 .

$=0.71)$; the opposite situation was found in the remaining $38 \%$ of cases $(\kappa: \lambda=1 \cdot 2)$.

The 17 patients with renal impairment in this group showed an equivalent enrichment in dimers $(59 \%$-that is, $10 / 17 \mathrm{M}: \mathrm{D}$ of $<1$ ) or monomers (41\% 7/17 M:D of $>1$ ), with a clear predominance of the $\lambda$ isotype $(\kappa: \lambda=$ 0.43 and 0.40 , respectively) in each category.

In 25 of the 58 patients immunoblotting showed the presence of small fragments reacting with the free light chain antiserum, with a molecular mass estimated at 14 kilodaltons.

\section{ISOELECTRIC POINTS}

The frequency distribution of the pI showed a bimodal pattern: $55 \%(51 / 92)$ of the BJP isolates had a pI of $<6(\bar{x}=5 \cdot 2)$ and $45 \%$ $(41 / 92)$ had a pI of $>6(\bar{x}=7 \cdot 5)$ (fig 5$)$.

In 68 of the 92 patients in whom we characterised the isotype of a circulating monoclonal immunoglobulin heavy chain, monoclonal IgG (31/92 cases) was accompanied in $29 \%$ $(9 / 31)$ of cases by a BJP with a pI above 6 . This proportion was $45 \%(10 / 22)$ for IgA $(22 / 92)$ and $63 \%(5 / 8)$ for IgM (8/92). In the patients whose circulating monoclonal protein was formed only of free light chains (25/92) $48 \%(12 / 25)$ of the urinary BJP isolates had a pI of $>6$.

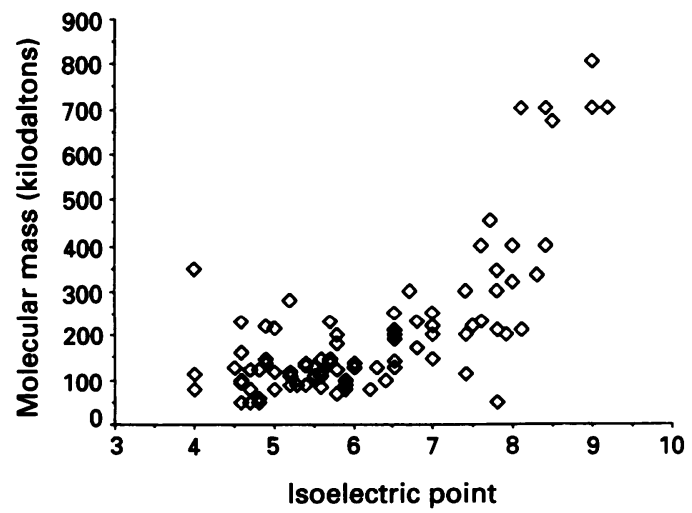

Figure 6 Correlation between electrophoretic ("migrational" molecular mass) and the isoelectric point of 92 BfP isolates. The correlation is positive $(r=0.78)$ for the BfP isolates $(n=41)$ with a high isoelectric point $(p I>6)$. 
Figure 7 Percentage distribution of 92 B尹P isolates from patients with renal impairment (RI) and those with normal renal function (NIR), according to the isoelectric point (BfP of $p I<6$, $n=51 ; B \mathcal{B}$ of $p I>6$, $n=41)$, and the isotype of the light chain. RI $\kappa:(\square)$ $R I$ i: ( $\square)$; NIR $\kappa:(\mathbb{Z})$; NIR i: (目).

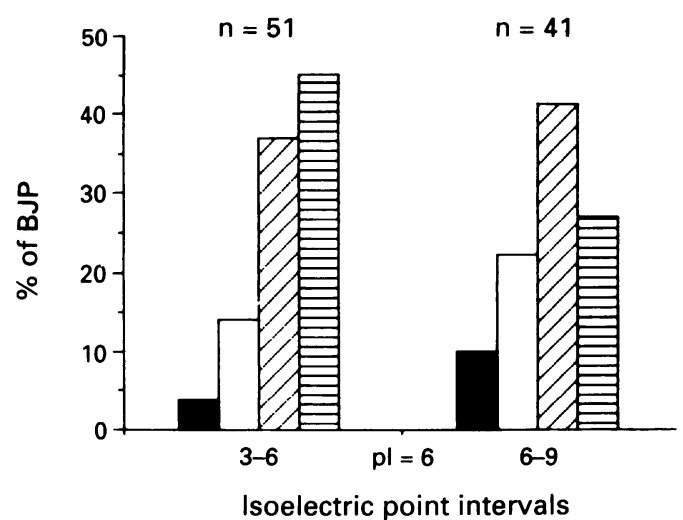

There was a correlation between the "migrational" molecular mass obtained in native conditions and the $\mathrm{pI}$, when the latter was above $6(\mathrm{r}=0.78 ; \mathrm{n}=41)$ (fig 6$)$. This correlation was observed regardless of the monomer/dimer composition.

In the group of patients with renal impairment the mean pI was $6 \cdot 3$ compared with $6 \cdot 1$ in the patients with normal renal function. The difference was not significant, but there was a different distribution of BJP. Among the $\mathrm{BJP}$ isolates with a pI of $<6,18 \%(9 / 51)$ were from patients with renal impairment, while among those with a pI of $>6,32 \%$ (13/41) were from patients with renal impairment. In each of these categories the $k: \lambda$ ratio was less than 1 (respectively, 0.3 and 0.4 ), indicating a clear predominance of the $\lambda$ isotype in the patients with renal impairment (fig 7).

\section{FERGUSON PLOTS}

These plots, established with $10 \mathrm{BJP}$ isolates (fig 8), showed that variations in BJP mobility as a function of the acrylamide concentration were linear. The slope of the lines was related to the size of the protein, and interestingly the lines had the same slope. This indicates that the BJP isolates studied had the same retardation coefficient and thus the same size. The different intersections extrapolated on the $y$ axis also showed large differences in the net charges of the BJP.

\section{TITRATION CURVES}

The titration curves for $10 \mathrm{BJP}$ isolates selected according to their $\mathrm{pI}$ (table 2) showed that the BJP behaved differently when placed in the same $\mathrm{pH}$ gradient. Three types of behaviour were defined (fig 9):

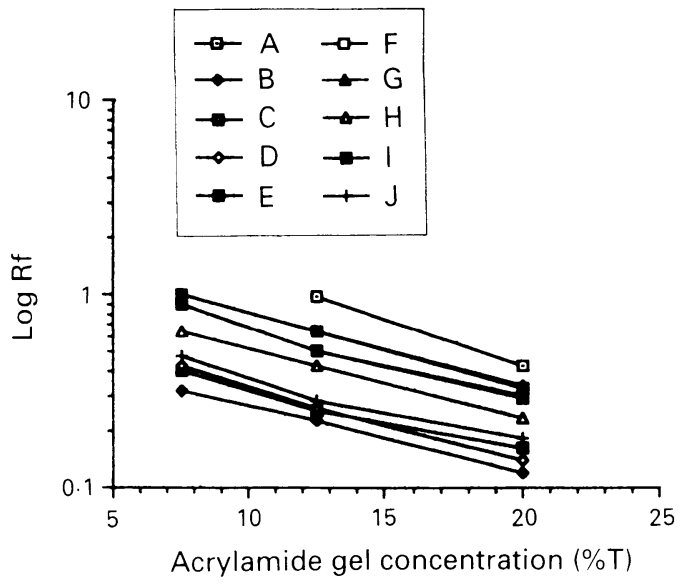

Figure 8 Ferguson plots: migration of 10 BfP isolates in polyacrylamide gels at three different concentrations $(T=7 \cdot 5,12 \cdot 5$, and $20 \%$ ).

(1) BJP type a, with acid pI (in our study $4 \cdot 7$ and 4.9 ), which were the most mobile, even at $\mathrm{pH}$ values close to their pI. They were strongly charged and behaved similarly to albumin $(\mathrm{n}=2)$.

(2) BJP type b, with $5.7<$ pI $<6.5$, with poor mobility, even when the $\mathrm{pH}$ varied by one unit either side of the $\mathrm{pI}$, probably indicating a weaker charge $(n=7)$.

(3) BJP type c, with a pI above 7 , which only took a positive charge. Its mobility increased gradually as the $\mathrm{pH}$ fell, indicating a strong positive charge at acid $\mathrm{pH}(\mathrm{n}=1)$.

Of the 10 titration curves, six were for BJP from patients with renal impairment, and five of these six took a weak negative charge at $\mathrm{pH}$ 7. These 10 titration curves also enabled us to detect the emergence of isoforms at distinct acid or alkaline $\mathrm{pH}$ values in three cases (fig 10).

STATISTICAL ANALYSIS

The data for the patients with renal impairment were examined to determine their predictive value for the onset of renal impairment. Three factors were taken into account: the isotype of the light chains; their "migrational" molecular mass in an acrylamide gradient, and their pI. The results of the unifactorial analysis showed that only the isotype of the light chain was predictive of the onset of renal impairment $(\mathrm{p}<0.05)$. Patients excreting a $i$ type BJP had a $2 \cdot 8$-fold higher risk of developing renal impairment compared

Table 2 Physico-chemical characteristics of 10 BfP isolates from patients with renal impairment $(n=6)$ and patients with normal renal function $(n=4)$ for which titration curves were constructed

\begin{tabular}{|c|c|c|c|c|c|}
\hline BfP isolate & $\begin{array}{l}\text { Serum } \\
\text { monoclonal } \\
\text { component }\end{array}$ & $\begin{array}{l}\text { Molecular } \\
\text { mass } \\
\text { (kilodaltons) }\end{array}$ & $\begin{array}{l}\text { Isoelectric } \\
\text { point }\end{array}$ & $\begin{array}{l}\text { BfP } \\
\text { charge at } \\
\text { pH } 7\end{array}$ & $\begin{array}{l}\text { Renal } \\
\text { Impairment }\end{array}$ \\
\hline A & $\kappa$ & 180 & $5 \cdot 8$ & - & 0 \\
\hline B (case 19) & $\kappa$ & 200 & $6 \cdot 7$ & - & + \\
\hline C & $i$ & 135 & $6 \cdot 1$ & -- & 0 \\
\hline $\mathrm{D}$ (case 15$)$ & $\mathrm{IgG} i+i$ & 100 & $5 \cdot 9$ & - & + \\
\hline E & $\operatorname{IgA} k+k$ & $>700$ & $8-9$ & ++ & 0 \\
\hline $\mathrm{F}$ & $\operatorname{IgA} k+k$ & 130 & $4 \cdot 7$ & --- & 0 \\
\hline $\mathrm{G}($ case 1$)$ & $\operatorname{IgA} \lambda$ & 210 & $6 \cdot 5$ & - & + \\
\hline $\mathrm{H}$ (case 8$)$ & $\operatorname{Ig} A i+i$ & 140 & $4 \cdot 9$ & - & + \\
\hline I (case 3 ) & $\operatorname{IgA} i+\operatorname{IgG} i+i$ & 85 & $5 \cdot 6$ & --- & + \\
\hline $\mathrm{J}$ (case 14) & $\operatorname{IgD} \lambda+\lambda$ & 250 & $6 \cdot 5$ & - & + \\
\hline
\end{tabular}


Figure 9 Schematic representation of the three types of titration curves obtained with 10 BfP isolates. Type a: $n=2 p I<5)$; type $b$ : $n=7(5.7<p I<6.5)$ type c: $n=1(p I>7)$.

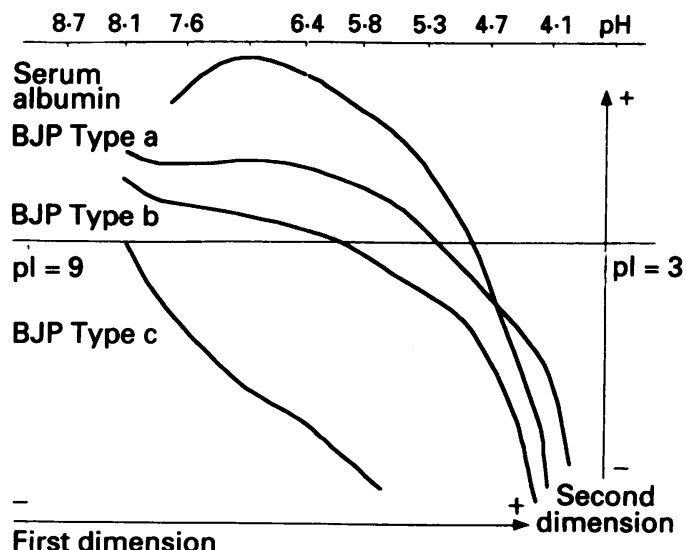

First dimension

with those excreting $\kappa$ type BJP. The multifactorial analysis confirmed that the isotype of the light chain was the only predictive factor.

\section{Discussion}

This study of $92 \mathrm{BJP}$ isolates using polyacrylamide gradient electrophoresis in native conditions shows that most BJP isolates had an apparent molecular mass greater than 50 kilodaltons, while the expected molecular mass was, at most, that of a dimer of two light chains of 214 amino acids and generally estimated at 45 kilodaltons. It was tempting to interpret these migration patterns as those of polymers or aggregates, which have often been reported. ${ }^{2028-31}$

Electrophoresis in the presence of SDS (in denaturing conditions) cannot show up this characteristic, given the dissociating effect of SDS. We found, in these conditions, that molecular mass values reflected the presence of monomers (molecular mass $=22.5$ kilodaltons) and dimers (molecular mass $=45$ kilodaltons), as generally described for this type of electrophoresis.

The Ferguson plots for $10 \mathrm{BJP}$ isolates, in native conditions, suggest that the "migrational" molecular masses in these conditions are simply apparent masses. They are, it seems, the expression of a particular protein charge, which confers poor mobility at the electrophoretic $\mathrm{pH}$, and an apparently raised molecular mass in the polyacrylamide gradients. This characteristic, already observed in gel filtration, ${ }^{32}$ was also reported in a study involving two-dimensional high resolution electrophoresis. ${ }^{33}$

The $\mathrm{pI}$ values of the BJP isolates we studied confirm the variability of this parameter..$^{24} 2534$ Two groups of BJP were also identified by Norden et al,${ }^{24}$ with a pI distribution similar to that in our study. Among the BJP isolates with a $\mathrm{pI}$ of more than 6 , there was a positive correlation between the pI and apparent masses. This observation, first made by Hill et al, ${ }^{18}$ who measured the mobility, relative to albu-

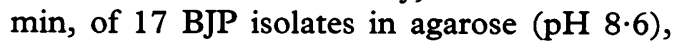
has also been observed by Norden et $a l^{24}$ for eight $\mathrm{BJP}$ isolates in agarose at $\mathrm{pH} 6$, using titration curves.

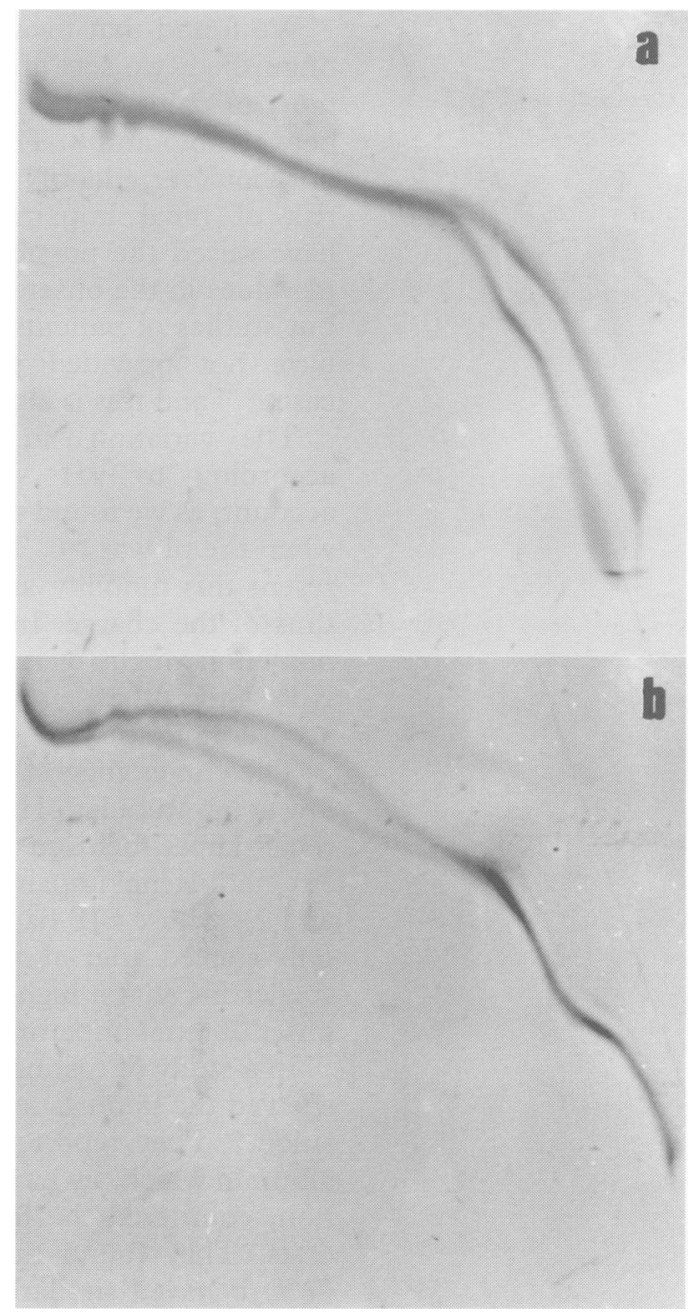

Figure 10 Titration curves for two BfP isolates (BFP A: $p I=5 \cdot 8 ; B f P C: p I=6 \cdot 1$ (table 2) showing the existence of isoforms in distinct $\mathrm{pH}$ zones (a: BFP $A$ : two isoforms; $b$ : BfP C: three isoforms).

We found three types of BJP, whose mobility was differently influenced by the $\mathrm{pH}$, indicating three different charges at physiological $\mathrm{pH}$. The presence of isoforms identified from the titration curves at different $\mathrm{pH}$ zones according to the BJP type explains some of the microheterogeneity observed in acrylamide gradient electrophoresis and in isoelectric focusing. A triple band in electrophoresis could be because of the charge difference of the three isoforms of a given molecule, which are separated at the precise $\mathrm{pH}$ at which the electrophoresis is carried out.

When these different parameters were examined according to renal function, we observed that the extreme characteristics (apparent masses and $\mathrm{pI}$ ) of the $\mathrm{BJP}$ isolate from case $\mathrm{E}$ (table 2) were never found in the other patients with renal impairment. However, we found an association between these two parameters and renal impairment. Indeed the latter seemed to be more common when the apparent mass of the BJP was raised and, as a result, its mobility lower. This association has been described by Hill et $a l^{18}$ in cast nephropathy, with an excellent correlation between poor mobility and the severity of renal impairment. 
We found that measurement of the pI distinguished two sets of patients with BJP, with most pI values falling between 4.5 and 6 , or between 6.5 and 8 . The cut off value of 6 did not, however, identify a population at a higher risk of renal impairment. Various authors have raised the possible involvement of high pI values in the onset of renal impairment, ${ }^{11} 19$ but studies of patients with renal impairment have not provided proof that this is the case, ${ }^{24-25}$ and this is also true of our data.

The variations in the mobility of BJP according to $\mathrm{pH}$ should be taken into account, as we found that mobility diminished when the $\mathrm{pI}$ was $>6$. The titration curves represent this mobility as a function of $\mathrm{pH}$ and thus of the charge. In the nephron this phenomenon might enable interactions between BJP and other proteins to be predicted according to the $\mathrm{pH}$.

The curves suggest that the BJP charge was low at intratubular $\mathrm{pH}$ in five of the six cases of renal impairment in which they were constructed. Renal impairment in case 3 (tables 1 and 2), whose BJP had a high charge at $\mathrm{pH} 7$, only started after about 10 years' follow up, suggesting that a high charge might delay the onset of renal impairment.

In a study of cast nephropathy Sanders et al showed the importance of urinary ion composition. ${ }^{17}$ They reported a protective effect of albumin which, by increasing chloride absorption, countered the formation of obstructive casts. They found that BJP with a high pI (7.7) behaved similarly-although capable of forming aggregates in vitro in the presence of Tamm-Horsfall protein, it did not give rise to this nephropathy in rats. More recently, the same authors showed that furosemide could aggravate the course of cast nephropathy, favouring cast formation by increasing the luminal sodium chloride concentration. ${ }^{35}$ These findings suggest that an interaction between the ion composition of intratubular urine and the degree of charge on the BJP could contribute to the nephrotoxicity of the latter.

In our study five of the 19 patients for whom data on possible confounding factors were available had no factors other than BJP likely to contribute to renal failure. This, together with the fact that none of these five patients recovered normal renal function after the episode of acute impairment, points to the nephrotoxic potential of BJP.

We did not find that electrophoretic physico-chemical characteristics of BJP (apparent mass and $\mathrm{pI}$ ) were predictive of the onset of renal impairment. However, immunochemical identification of the light chain isotype can provide information on the risk of renal failure, as previously reported by Alexanian et al. ${ }^{36}$ The pI remains informative, as it can be used to predict the BJP charge according to urinary $\mathrm{pH}$. None the less this criterion does not take into account the degree of charge, which may explain the interactions of BJP with other components of urine or tubule cells. Apparent masses, which can be measured in acrylamide gradients, would seem to reflect this charge. Only titration curves can describe the charge behaviour of the molecule, its variability at different $\mathrm{pH}$ values, and the possible existence of isoforms.

Studies of a wider variety of BJP will no doubt permit these proteins to be classified according to the type of renal impairment and help explain in vivo toxicity mechanisms.

1 Solomon A. Bence-Jones proteins and light chains of immunoglobulins. N Engl ₹ Med 1976;294:17-23.

2 Beaufils M, Morel-Maroger L. Pathogenesis of renal disease in monoclonal gammopathies. Current concepts. Nephron 1978;20:125-31.

3 Solomon A. Clinical implications of monoclonal light chains. Semin Oncol 1986;13:341-9.

4 Fang LST. Light-chain nephropathy. Kidney Int 1985;27: 582-92.

5 DeFronzo RA, Cooke CR, Wright JR, Humphrey RL. Renal function in patients with multiple myeloma. Medicine 1978;57:151-66.

6 Ganeval D, Jungers P, Noël LH, Droz D. La néphropathie du myélome. In: Hamburger J, Crosnier J, Funckdu myelome. In: Hamburger J, Crosnier J, FunckBrentano JL eds. Actualités néphrologiques
Necker. Paris: Flammarion, 1977;309-47.

7 Kyle RA. Subject Review: Multiple myeloma. Review of 869 cases. Mayo Clin Proc 1975;50:29-40.

8 DeFronzo RA, Humphrey RL, Wright JR, Cooke CR. Acute renal failure in multiple myeloma. Medicine 1975; 54:209-23.

9 Lenert P, Drazen F, Tepavcevic P, Pejin D, Curic S, Ilic $\mathrm{V}$, et al. Influence of Bence-Jones proteins, hyperviscosity, hypercalcemia, hyperuricemia and dehydration on development of renal changes in plasma cell dyscrasias. opment of renal changes in p
Przeglad Lekarski 1985;42:384-6.

10 Smolens P, Barnes JL, Kreisberg R. Hypercalcemia can potentiate the nephrotoxicity of Bence-Jones proteins. f Lab Clin Med 1987;110:460-5.

11 Clyne DH, Pesce AJ, Thompson RE. Nephrotoxicity of Bence-Jones proteins in the rat: Importance of protein isoelectric point. Kidney Int 1979;16:345-52.

12 Weiss JH, Williams RH, Galla JH, Gottschall JL, Rees ED, Bathena D, et al. Pathophysiology of acute Bence-Jones protein nephrotoxicity in the rat. Kidney Int 1981;20: 198-210.

13 Smolens P, Venkatachalam M, Stein JH. Myeloma kidney cast nephropathy in a rat model of multiple myeloma. Kidney Int 1983;24:192-204.

14 Smolens P, Barnes JL, Stein JH. Effect of chronic administration of different Bence-Jones proteins on rat kidney. Kidney Int 1986;30:874-82.

15 Sanders PW, Herrera GA, Galla JH. Human Bence-Jones protein toxicity in rat proximal tubule epithelium in vivo. Kidney Int 1987;32:851-61.

16 Sanders PW, Herrara GA, Chen A, Booker BB, Galla JH. Differential nephrotoxicity of low molecular weight proteins including Bence-Jones proteins in the perfused proteins including Bence-Jones proteins in the perfus

17 Sanders PW, Booker BB, Bishop JB, Cheung HC. Mechanisms of intranephronal proteinaceous cast formation by low molecular weight proteins. F Clin Invest 1990;85:570-6.

18 Hill GS, Morel-Maroger L, Mery JP, Brouet JC, Mignon F. Renal lesions in multiple myeloma: their relationship to associated abnormalities. Am $\mathcal{f}$ Kidney Dis 1983;2: 423-38.

19 Coward RA, Delamore IW, Mallick NP, Robinson EL. The importance of urinary immunoglobulin light chain isoelectric point (pI) in nephrotoxicity in multiple myeloma. Clin Sci 1984;66:229-32.

20 Sölling K, Sölling J, Lanng-Nielsen J. Polymeric BenceJones proteins in serum myeloma patients with renal
insufficiency. Acta Med Scand 1984;216:495-502.

21 Palant CE, Bonitati J, Bartholomew WR, Brentjens JR, Walshe JJ, Brentzel CJ. Nodular glomerulosclerosis associated with multiple myeloma: role of light chain isoelectric point. $A m \mathcal{F} M e d$ 1986;80:98-102.

22 Melcion C, Mougenot B, Beaudouin B, Ronco P, Moulonguet-Doleris L, Vanhille $P$, et al. Renal failure in myeloma: relationship with isoelectric point of immunoglobulin light chains. Clin Nephrol 1984;22: $138-43$.

23 Sturgill BC, Tucker FL, Bolton WK. Immunoglobulin light chains nephropathies. Pathol Annu 1987;22: 133-50.

24 Norden AGW, Flynn FV, Fulcher LM, Richard JDM Renal impairment in myeloma: negative association with isoelectric point of excreted Bence-Jones protein. $\mathcal{f}$ Clin isoelectric point of exc.

25 Johns EA, Turner R, Cooper EH, Maclennan ICM. Isoelectric points of urinary light chains in myelomatosis: analysis in relation to nephrotoxicity. $\mathcal{F}$ Clin Pathol 1986; 39:833-7.

26 Jackson PJ, Sampson CJ, Cooper EH, Heney D, Brocklebank JT. Analysis of proreinuria using a commercial system for automated electrophoresis and isoelectric focusing. Ann Clin Biochem 1988;25:319-24. 
27 Charlionnet R, Rivat C. Electrophorèse. In: Principes et concepts méthodologiques. Paris: INSERM, 1990:106-7.

28 Bernier GM, Putnam FW. Polymerism, polymorphism, and impurities in Bence-Jones proteins. Biochem Biophys Acta 1964;86:295-308.

29 Berggard I, Peterson PA. Polymeric forms of free normal kappa and lambda chains of human immunoglobulins. $\mathscr{f}$ Biol Chem 1969;244:4299-307.

30 Tan M, Epstein W. Polymer formation during the degradation of human light chain and Bence-Jones proteins by an extract of the lysosomal fraction of normal human kidney. Immunochemistry 1972;9:9-16.

31 Deegan MJ. Bence-Jones proteins: nature, metabolism, detection and significance. Ann Clin Lab Sci 1976;6: 38-46.

32 Stevens FI, Westholm FA, Solomon A, Schiffer M. Self association of Kappa 1 subunits: role of the third hyper- variable region. Proc Natl Acad Sci USA 1980;77: 1144-8.

33 Foldfarb MF, Portland AEP. Two-dimensional electrophoretic analysis of immunoglobulin patterns in monoclonal gammopathies. Electrophoresis 1992;13:440-4.

34 Rota S, Mougenot B, Baudouin B, de Meyer-Brasseur M Lemaitre V, Michel C, et al. Multiple myeloma and severe renal failure: a clinicopathologic study of outcome and prognosis in 34 patients. Medicine 1987;66: $127-39$.

35 Sanders PW, Booker BB. Pathobiology of cast nephropathy from human Bence-Jones proteins. $\mathcal{F}$ Clin Invest 1992;89:630-9.

36 Alexanian R, Haut A, Khan AU, Lane M, McKelvey EM, Migliore PJ, et al. Treatment for multiple myeloma. Combination chemotherapy with different melphalan dose regimens. $¥ A M A$ 1969;208:1680-5. 